\author{
UnB - UNIVERSIDADE DE BRASÍLIA \\ CET - CENTRO DE EXCELÊNCIA EM TURISMO \\ COORDENAÇÃO DE PÓS-GRADUAÇÃO GESTÃO DA HOSPITALIDADE
}

\title{
ACESSIBILIDADE DE PESSOAS PORTADORAS DE DEFICIÊNCIA AOS HOTÉIS DE BRASÍLIA
}

\author{
Ana Cristina Lopes da Silva
}

Orientador drs. Philippus Johannes Heijblom

Monografia apresentada ao Centro de

Excelência em Turismo da

Universidade de Brasília como requisito parcial para a obtenção do certificado de Especialista em Gestão da Hospitalidade. 
UNIVERSIDADE DE BRASÍLIA

Centro de Excelência em Turismo

Curso de Especialização em Gestão da Hospitalidade

\title{
ACESSIBILIDADE DE PESSOAS PORTADORAS DE DEFICIÊNCIA AOS HOTÉIS DE BRASÍLIA
}

\author{
Ana Cristina Lopes da Silva
}

Banca Examinadora
drs. Philippus Johannes Heijblom Orientador

Brasília, 30 de Janeiro de 2004 
Ana Cristina Lopes da Silva

\section{ACESSIBILIDADE DE PESSOAS PORTADORAS DE DEFICIÊNCIA AOS HOTÉIS DE BRASÍLIA}

Comissão Avaliadora

drs. Philippus Johannes Heijblom

Professor(a)

Professor(a)

Brasília, DF, 30 de janeiro de 2004. 


\section{RESUMO}

Nesta monografia pretende-se avaliar as condições de acessibilidade de Pessoas Portadoras de Deficiência nos hotéis de Brasília. Foi feito um levantamento sobre as condições de acessibilidade nos hotéis de Brasília, de acordo com as orientações do Manual de recepção e acessibilidade de pessoas portadoras de deficiência a empreendimentos e equipamentos turísticos. A pesquisa realizada nos hotéis da cidade procurou identificar se os hotéis possuem os itens indispensáveis para a acessibilidade de pessoas portadoras de deficiência, rampas, barras sanitárias e outros.

O resultado do trabalho foi positivo, chegou-se a conclusão de que os hotéis em Brasília ainda não estão totalmente adaptados para receber pessoas portadoras de deficiência.

Palavras chave : Hotel, Acessibilidade, Pessoas portadoras de deficiência 


\begin{abstract}
This monograph pretends to evaluate the conditions of accessibility of handicaps people to the hotels of Brasília. The conditions of accessibility of the hotel of Brasília were evaluated according to the orientations of the Manual of reception and accessibility of handicaps people to turistical establishments and equipments. The research realized in the hotels of the city tried to identifify if the hotels have the indispensable itens for the access of handicaps people, such as slopes, handgrips and others.
\end{abstract}

The Result of this work was positive. Conludes was that the hotels in Brasilia are not yet totally adapted to receive handicaps people.

Keys words: Hotel, accessibility, handicaps people. 


\section{SUMÁRIO}

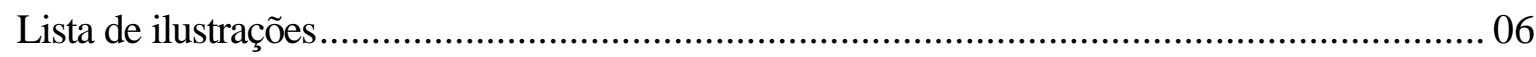

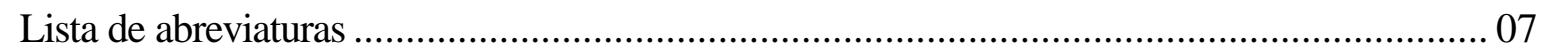

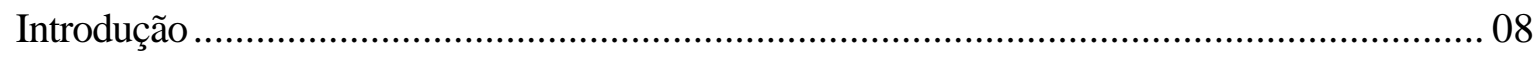

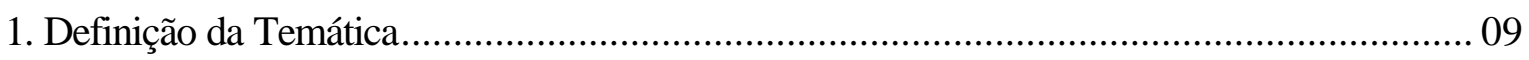

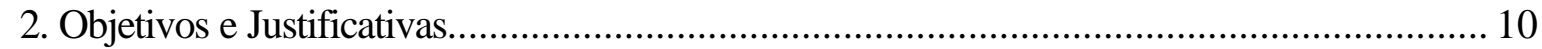

3. Quem são os portadores de deficiência?............................................................. 11

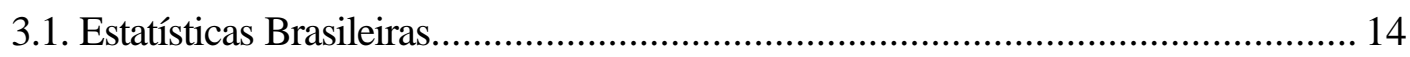

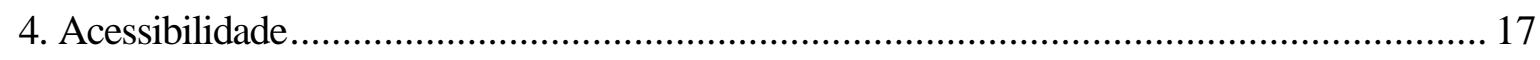

4.1. Arquitetura e Barreiras Arquitetônicas .......................................................... 19

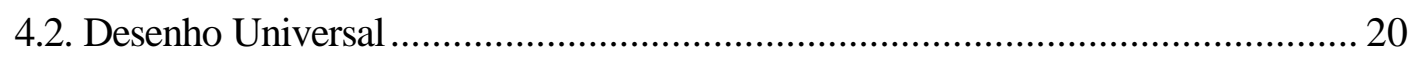

5. A legislação e os direitos dos portadores de deficiência no Brasil ................................... 21

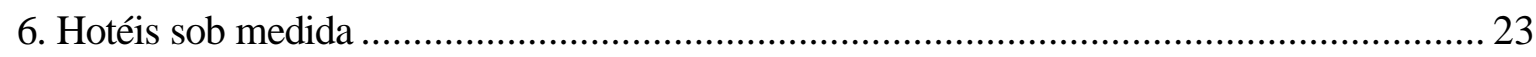

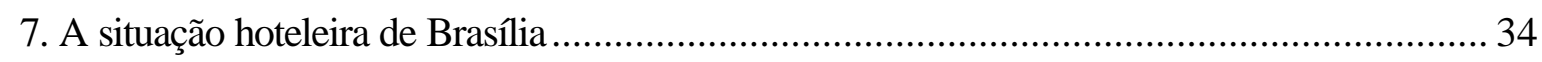

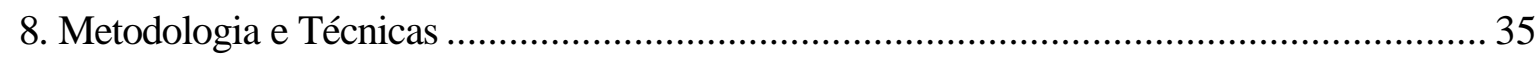

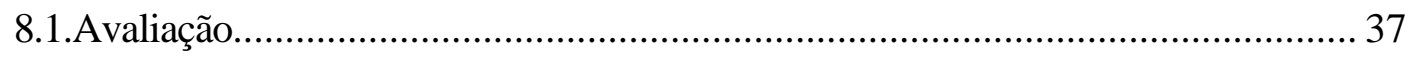

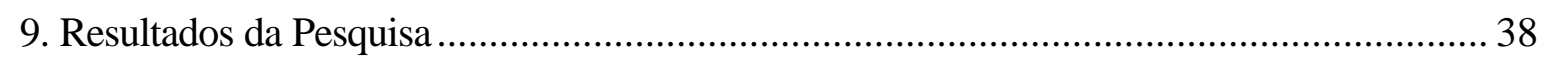

9.1. Adaptação dos hotéis ............................................................................ 39

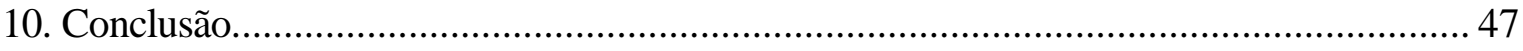

Referências Bibliográficas .................................................................................... 49

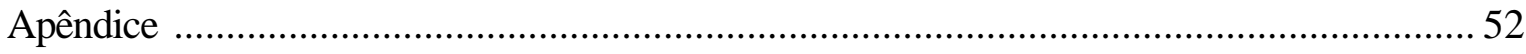




\section{LISTA DE ILUSTRAÇÕES}

Figura 1: diâmetro de rotação de uma cadeira de rodas......................................................28

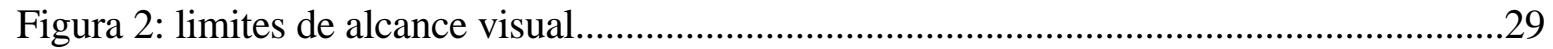

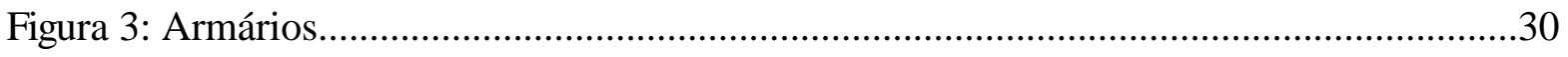

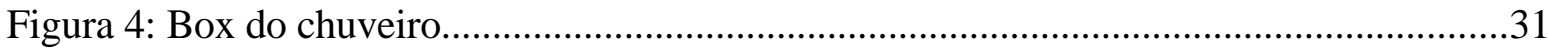

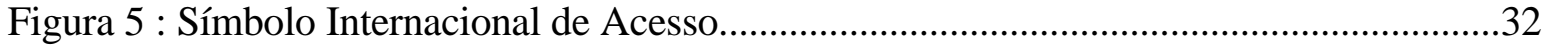

Tabela 1: número de deficiências detectadas....................................................................14

Tabela 2 : Dimensionamento de rampas..........................................................................25 


\section{LISTA DE ABREVIATURAS}

$\begin{array}{ll}\text { ABIH } & \text { Associação Brasileira da Industria de Hotéis } \\ \text { EMBRATUR } & \text { Instituto Brasileiro de Turismo } \\ \text { PPD } & \text { Pessoa Portadora de Deficiência } \\ \text { UH } & \text { Unidade Habitacional } \\ \text { ABNT } & \text { Associação Brasileira de Normas Técnicas } \\ \text { NBR } & \text { Normativa Brasileira } \\ \text { CORDE } & \text { Coordenadoria Nacional para a Integração da Pessoa Portadora de Deficiência } \\ \text { PAME } & \text { Organização das Nações Unidas } \\ \text { OMS } & \text { Organização Mundial de Saúde } \\ & \\ & \end{array}$




\section{INTRODUÇÃO}

Muitas pessoas portadoras de deficiência não têm garantido o direito de ir e vir em áreas públicas. Nos hotéis não é diferente, muito tem se falado sobre acessibilidade, muitas leis foram criadas para garantir o acesso aos espaços pelas pessoas portadoras de deficiência mas a realidade mostra que as leis estão longes de serem cumpridas.

Com o aumento da participação das pessoas portadoras de deficiência em atividades que antes só eram praticadas por pessoas não portadoras de deficiência, tais como olimpíadas, jogos de tênis, eventos e atividades turísticas surgiu a necessidade de hotéis adaptados para receber esse público

O trabalho versará sobre a acessibilidade de pessoas portadoras de deficiência aos hotéis de Brasília. Os seguintes conceitos serão abordados no decorrer do trabalho: acessibilidade, barreiras arquitetônicas, quem são as pessoas portadoras de deficiência, a evolução dos direitos das pessoas portadoras de deficiência e as orientações da Embratur, feitas através do Manual de recepção e acessibilidade de pessoas portadoras de deficiência aos empreendimentos e equipamentos turísticos.

O objetivo do trabalho é identificar se os hotéis de Brasília estão adaptados para receber pessoas portadoras de deficiência. Para alcançar os resultados da pesquisa foram utilizadas metodologias qualitativas e quantitativas.

Por se tratar de um tema de grande importância social este trabalho contribuirá para os hoteleiros revejam a situação atual de acessibilidade de pessoas portadoras de deficiência nos hotéis. 


\section{1-DEFINIÇÃO DA TEMÁTICA}

Nos últimos anos a acessibilidade de pessoas portadoras de deficiência vem tendo uma maior abordagem, há uma preocupação progressiva com o tema, tanto na concepção de novos projetos como na adequação dos espaços existentes.

Na reportagem Cadê a rampa? publicada no Correio Braziliense de 18 de Junho de 2003, Mariana Ceratti conclui que as barreiras arquitetônicas são alguns dos principais entraves ao acesso e à utilização dos meios de hospedagem. Segundo a autora em alguns casos os portadores de deficiência não são atendidos pelos meios de hospedagem em suas necessidades mais elementares. Muitos hotéis não possuem rampas, patamares, portas e sinalizações especiais, que garantam a circulação e a acessibilidade a edificações e equipamentos do hotel. Tarefas fáceis como tomar um banho torna-se um transtorno devido a falta de um banheiro amplo, adequado com pias e duchas na altura adequada para cadeiras de rodas, barras de apoio e outros itens necessários para acessibilidade de PPD.

Garantir o acesso dos Portadores de Deficiência aos hotéis é fundamental para que esse público usufrua das atividades turísticas. 


\section{2- OBJETIVOS E JUSTIFICATIVAS}

O objetivo desta pesquisa é realizar um levantamento das condições de acessibilidade de pessoas portadoras de deficiência nos hotéis de Brasília. A pesquisa abordará os hotéis a partir de duas perspectivas:

- Hotéis pertencentes a redes hoteleiras;

- Hotéis "tradicionais" (administração própria)

O trabalho identificará se os hotéis da cidade estão adaptados, com instalações para portadores de deficiência de acordo com as orientações do Manual de recepção e acessibilidade de portadores de deficiência a empreendimentos e equipamentos turísticos . O manual segue os padrões e critérios ditados pela NBR 9050/94 ABNT - Acessibilidade de pessoas portadoras de deficiência a edificações, espaço, mobiliário e equipamentos urbanos.

A inclusão social do portador de deficiência e a conquista de uma vida independente são fundamentais para sua integração à sociedade. Garantir o direito de ir e vir e atender as suas necessidades especiais, de forma igual e sem preconceitos .

Muitas Pessoas Portadoras de Deficiência (PPD) têm uma vida social ativa, viajam

constantemente a serviço ou em busca de lazer. Identificar e atender as necessidades dessa clientela é de fundamental importância para os empreendedores do setor hoteleiro. 


\section{3- QUEM SÃO OS PORTADORES DE DEFICIÊNCIA ?}

Segundo Cancella (1994, pág. 30) o conceito de Pessoas Portadoras de deficiência obteve diversos sentidos e interpretações ao longo do tempo . "Encontra-se atitudes de repúdio e extermínio". São diversos os termos utilizados para se referir a um grupo composto por "pessoas portadoras de deficiência": aleijado, mutilado, inválido, indivíduo de capacidade limitada, deficiente e etc. As palavras e suas correlações são os reflexos das imagens que são feitas destas pessoas, tornando-se à sua maneira coisa concretas de nossa realidade.

As diferentes culturas adotam diversos termos:

Os franceses utilizam uma definição por oposição: os válidos em relação aos inválidos, os ingleses adotam “disabled”, os espanhóis : “minusválidos”.

O conceito encontrado nos dicionários de língua portuguesa revela que as idéias mais adotadas são as de falta, carência e de falha sensorial, motora ou mental, seriam pessoas deficientes.

A definição adotada pela Organização das Nações Unidas (ONU) em sua "Declaração dos Direitos das Pessoas Deficientes" de 9 de dezembro de 1975 , aprovada em Assembléia Geral:

"O termo pessoas deficientes refere-se a qualquer pessoa incapaz de assegurar por $\dot{\mathbf{s}}$ mesma, total ou parcialmente, as necessidades de uma vida individual ou social normal, em decorrência de uma deficiência congênita ou não, em suas capacidades físicas, sensoriais ou mentais"

Os termos utilizados pelos países que formam as Nações Unidas são: "Disability” (em inglês), "discapacidad" (em espanhol ) e "handicap" (em francês) . 
No Brasil utilizou-se por muito tempo a palavra "excepcional", posteriormente adotou a palavra "deficiente" para designar estas pessoas . Atualmente utiliza-se a nomenclatura "portadores de deficiência" que caracteriza que a deficiência está no corpo da pessoa e não é a pessoa que é deficiente.

A terminologia "pessoas portadoras de necessidades especiais" também é aceita pela área técnica.

Quando se fala das "Pessoas Portadoras de Deficiência" em geral imaginam-se somente os deficientes físicos que se locomovem em cadeira de rodas. No entanto, existem diferentes tipos e níveis de deficiência.

Os artigos $3^{\mathrm{o}}$ e $4^{\mathrm{O}}$ do Decreto n. 3298, de 20 de dezembro de 1999, que regulamenta a Lei 7.853 , de 24 de dezembro de 1989, e dispõe sobre a Política Nacional para a Integração da Pessoa Portadora de Deficiência, considera pessoa portadora de deficiência a que se enquadra nas seguintes categorias : Deficiência física, Deficiência auditiva, Deficiência visual. Deficiência mental e Deficiência múltipla. Para efeito da pesquisa serão consideradas as definições de Deficiência física, Deficiência auditiva e Deficiência visual.

O Decreto n.3298/99 conceitua os seguintes tipos de deficiência:

"Deficiência física: alteração completa ou parcial de um ou mais segmentos do corpo humano, acarretando o comprometimento da função física, apresentando-se sob a forma de paraplegia, paraparesia, monoplegia, monoparesia, tetraplegia, tetraparesia, triplegia, triparesia, hemiplegia, hemiparesia, amputação ou ausência de membro, paralisia cerebral, membros com deformidade congênita ou adquirida, exceto as deformidades estéticas as que não produzam dificuldades para o desempenho de funções.

-Deficiência auditiva: perda parcial ou total das possibilidades auditivas sonoras, variando em grau e nível, desde surdes leve à perda total da audição. 
- Deficiência Visual: acuidade visual igual ou menor que 20/200 no melhor olho, após a melhor correção, ou campo visual inferior a 20 (tabela de snellen), ou ocorrência simultânea de ambas as situações." (Decreto n.3298/99 Lei 7853)

Segundo o Decreto Federal n. 914/93 , o PPD é "aquela pessoa que apresenta, em caráter permanente, perdas ou anomalias de sua estrutura ou função psicológica, fisiológica ou anatômica, que gerem incapacidade para o desempenho de atividades, dentro do padrão considerado normal para o ser humano"

Segundo Manual de recepção e acessibilidade de pessoas portadoras de deficiência a empreendimentos e equipamentos turísticos, da Embratur, portadores de deficiência são as pessoas com deficiências, temporárias ou permanentes, que, sem condições especiais de recepção e acessibilidade à infra-estrutura, não têm como se utilizar, com segurança e autonomia, das edificações e equipamentos de interesse turístico e, em conseqüência de participar da atividade turística.

O manual considera os portadores de deficiência as pessoas com:

- deficiência ambulatória total, que lhes obrigue a utilizar, temporária ou permanentemente, cadeiras de rodas;

- deficiência ambulatória parcial, que lhes traga dificuldade ou insegurança de movimentos, obrigando-lhes, ou não, ao uso de aparelhos ortopédicos e próteses;

- deficiência sensorial visual; com perda total ou parcial da audição, capaz de lhes trazer idêntica insegurança ou desorientação .

No presente trabalho será utilizado o conceito encontrado no Manual de recepção e acessibilidade de pessoas portadoras de deficiência a empreendimentos e equipamentos turísticos, mencionado no parágrafo anterior. 


\subsection{AS ESTATÍSTICAS BRASILEIRAS DE PPD}

Segundo dados da Organização Mundial de Saúde, existem 500 milhões de deficientes no mundo, um décimo da raça humana. Das pessoas com deficiência, $80 \%$ vivem em países em desenvolvimento.

No Brasil, o Censo 2000 - IBGE, revela que aproximadamente 24,5 milhões de pessoas, cerca de $14,5 \%$ da população brasileira são portadoras de algum tipo de deficiência.

Tabela 1: número de deficiências detectadas

\begin{tabular}{|l|l|}
\hline $\begin{array}{l}\text { Número de deficiências } \\
\text { detectadas }\end{array}$ \\
\hline Visual & 11,77 \\
\hline Motora & 5.6 \\
\hline Auditiva & 4,08 \\
\hline Mental & 2,09 \\
\hline Física & 0,99 \\
\hline Total & 24,5 \\
\hline \hline
\end{tabular}

Fonte:www.ibge.gov.br

A promulgação da Lei no 7.853, de 24 de outubro de 1989, trouxe,entre outras garantias legais, a obrigatoriedade de se incluir nos censos nacionais questões específicas sobre as pessoas portadoras de deficiência, uma vez que o estudo dessa população alvo passou 
a constituir condição indispensável para sustentar a definição de medidas específicas mais adequadas à realidade nacional.

As questões formuladas privilegiaram o estudo das incapacidades como ponto de partida para a identificação das deficiências e do grau de comprometimento

O Censo Demográfico 2000, revelou que o percentual de pessoas que declararam possuir pelo menos uma deficiência ou incapacidade é de 14,3\% nas zonas urbanas e 15,2\% nas zonas rurais. O Sudeste é a região que tem a menor proporção de pessoas que declararam serem portadoras de deficiência $(13,1 \%)$. Já o Nordeste apresenta o maior percentual de portadores de deficiência, 16,8 (Censo Demográfico 2000)

Analisando a inserção da população ocupada nas diversas atividades econômicas, observa-se que, de modo semelhante ao verificado em outros países, muitas pessoas que se declaram portadoras de deficiência trabalham na agropecuária e atividades relacionadas.

Em particular, 25\% do total das pessoas com pelo menos uma deficiência trabalha nesse tipo de atividade, enquanto somente $17 \%$ do total de pessoas ocupadas sem nenhuma das deficiências investigadas ocupa-se nesses setores.

Por outro lado, também como eram esperadas, proporções relativamente maiores de pessoas ocupadas sem deficiências trabalham na indústria de transformação e no comércio. Situação análoga observa-se com respeito aos grupos ocupacionais: as pessoas portadoras de deficiência são em maior proporção os trabalhadores na agropecuária, florestais ou serviços relacionados.

As maiores diferenças entre as proporções das pessoas ocupadas sem deficiências e as portadoras de pelo menos uma deficiência estão associadas aos trabalhadores de serviços administrativos, técnicos de nível médio e profissionais das ciências e artes. 
No Censo 2000 observa-se que a proporção de homens que ganha até um salário mínimo é de 20,2\%,enquanto, para as mulheres, essa proporção é de $28,5 \%$. Quando são consideradas as pessoas que se declaram portadoras de pelo menos uma deficiência, estas proporções passam a ser $25,7 \%$ e $35,7 \%$, respectivamente. No caso da deficiência mental, $30,5 \%$ dos homens e $33,1 \%$ das mulheres que trabalham percebem até um salário mínimo.

O Censo 2000 mostra que incapacidade e pobreza estão estreitamente relacionadas. A incapacidade aumenta a probabilidade de se viver em condições precárias, que, por sua vez, aumentam o risco de ser portador de deficiência.

O Censo Demográfico revelou que as pessoas com incapacidade têm níveis mais baixos de educação, de rendimentos e de participação m mercado de trabalho. Além disso, a inserção na força de trabalho se concentra em ocupações e atividades que exigem menor especialização. Contudo, esta inserção varia de acordo com o tipo de deficiência e com o grau de severidade da mesma. 


\section{4- ACESSIBILIDADE}

Acessibilidade é definida pela ABNT- Associação Brasileira de Normas Técnicas ,pela norma NBR 9050/94 - Acessibilidade de pessoas portadoras de deficiências a edificações, espaço mobiliário e equipamentos urbanos ,como sendo...... "A possibilidade e condição de alcance para utilização, com segurança e autonomia, de edificações, espaço, mobiliário e equipamento".

O Setor de Arquitetura e Engenharia SAE da Subcoordenadoria para integração das pessoas Portadoras de Deficiência (CORDE/Ministério da Justiça) considera as seguintes categorias de acessibilidade:

"Acesso como a capacidade de se chegar a outras pessoas . Os seres humanos são entes sociais e o contato entre eles torna-se necessário para o bem estar de todos. Essa é a visão dos espaços coletivos como cenário de troca entres as diferentes pessoas.

A acessibilidade surge como tributo imprescindível na sociedade , permitindo que todos possam desfrutar das mesmas oportunidades em trabalho, educação, habitação, lazer turismo e cultura.

Através da comunicação sensorial, reprodução dos significados da vida comum pelas formas, cores, texturas, sons e signos expressos em cada espaço e mobiliário urbanos, é possível realizar um sistema de sinalização acessível a qualquer pessoa .

A acessibilidade pressupõe a liberdade de escolha ou a opção individual no ato de relacionar-se com o ambiente e com a vida . Basear-se na idéia que as pessoas portadoras de deficiência dependem da ajuda de terceiros gera situações constrangedoras. 
$\mathrm{O}$ acesso ao meio físico. O planejamento da boa forma da cidade, levando em consideração a acessibilidade ao meio físico, possibilitará a construção de uma sociedade inclusiva que assimile progressivamente a idéia de integração social e espacial das pessoas com todas as suas diferenças."

(SAE,2000) 


\section{1 - ARQUITETURA E BARREIRAS ARQUITETÔNICAS}

Em muitos ambientes encontram-se barreiras que dificultam a acessibilidade aos espaços. Para as pessoas que não possuem nenhum problema de locomoção as barreiras passam despercebidas, mas a arquitetura é injusta com os PPD. Os obstáculos presentes em empreendimentos discriminam essa parcela da população ao negar-lhes a possibilidade de usufrui-los.

Segundo o arquiteto José Almeida Lopes Filho, especialista em acessibilidade, a arquitetura desenvolve um papel importante na história, no processo de compreensão da sociedade como um todo único. Toda e qualquer idéia ou projeto deve ter um nascer respeitando o conceito de "acessibilidade para todos". Os portadores de deficiência tem o livre direito de locomover-se. ${ }^{1}$

“A eliminação das barreiras arquitetônicas e entendimento de que novas barreiras não devem ser construídas passará a ser uma realidade para profissionais como arquitetos, engenheiros, urbanistas, pois devemos planejar, projetar e construir levando e consideração a limitações, capacidades e necessidades que as pessoas apresentam... devemos entender que não são as pessoas que são portadoras de deficiência e sim as edificações, transportes, praças, as cidades em geral, que são planejados e projetados com conceitos ultrapassados, ineficientes para o uso do homem".

(Lopes, 2000)

Segundo Adriana Romeiro de Almeida, arquiteta urbanista, técnica da Fundação Prefeito Faria Lima - CEPAM, " é preciso tornar as cidades mais humanas, eliminando os riscos de acidentes e integrando melhora pessoas portadoras de deficiência." Adriana afirma ainda que " tornar o espaço acessível, é eliminar obstáculos físicos, naturais ou de comunicação que existam nas cidades, nos equipamentos imobiliários urbanos, nos edifícios, nas várias modalidades de transporte público que impeçam ou dificultem a livre circulação de pessoa",

\footnotetext{
${ }^{1}$ Comentários obtidos no texto :O direito de ir e vir com Independência, disponível em www.entreamigos.com.br

${ }^{2}$ Comentários obtidos no texto: Ambientes Acessíveis, disponível em www.entreamigos.com.br
} 


\subsection{DESENHO UNIVERSAL}

Em 1963 foi criada em Washington-EUA uma comissão para um " Desenho Livre de Barreiras", que se constituía e uma corrente ideológica para o desenho de equipamentos, edifícios e áreas urbanas. Nessa linha de pensamento os fatores comportamentais são associados às barreiras existentes, onde a exclusão e a segregação das pessoas portadoras de deficiência desses obstáculos. ${ }^{3}$

Segundo SAE - Serviço de Engenharia e Arquitetura (CORDE) o desenho universal não abrange apenas os PPD; leva em consideração as múltiplas diferenças existentes entre as pessoas . Propõe que os espaços sejam projetados de forma a atender ampla gama da população, considerando as variações de tamanho, sexo, peso, ou diferentes habilidades ou limitações que as pessoas possam ter.

São princípios básicos do Desenho Universal:

- Acomodar grande gama antropométrica, ou seja, pessoas de diversos padrões ou em diferentes situações (altos, baixos, em pé, sentados, etc). Significa estar atento a alguns limites de ação e alcance manual ou visual impostos a pessoas mais baixas, mais altas, ou em cadeiras de rodas, por exemplo:

- Reduzir a quantidade de energia necessária para utilizar produtos ou ambiente. Deve-se adequar as distâncias e espaços para que não levem a um esforço adicional ou cansaço físico

- Adequar ambientes e produtos, para que sejam mais compreensíveis, considerando, inclusive, as pessoas com perdas visuais ou auditivas que necessitam de soluções especiais através de cores vibrantes ou sinais sonoros;

- Interrelacionar os produtos e ambientes, que devem ser concebidos como sistemas e não mais como partes isoladas. (CORDE /SAE 2000)

\footnotetext{
${ }^{3}$ Subcoordenadoria de arquitetura e engenharia, disponível em www.corde.rn.gov.br/arquitetura
} 


\section{A LEGISLAÇÃO E OS DIREITOS DOS PORTADORES DE DEFICIÊNCIA NO BRASIL}

Oliveira (1981 ) cita que nos povos primitivos, aqueles que não tinham utilidade para o trabalho ou para a guerra, eram eliminados. Na lei das XII Tábuas, por exemplo, antigo código de Roma, a Tábua IV estabelecia que o filho nascido "monstruoso" deveria ser morto imediatamente, cabendo ao pai da criança extermina-la. Diante dessa lei , era comum a exposição de crianças à margem dos rios ou lugares sagrados para serem mortas, após terem sido mostradas a cinco vizinhos para que comprovassem as anomalias física e ou mentais.

Segundo Villatore (1999) no século XIX, a partir da Revolução industrial, surgiu uma nova legião de mutilados advindo do precário trabalho nas indústrias. As guerras também trouxeram como consequiência os portadores de deficiência física, fazendo com que vários países elaborassem legislação com a finalidade de proteger essa categoria de trabalhadores.

No Brasil houve uma grande evolução da legislação em favor dos portadores de deficiência e para garantia dos seus direitos.

A partir de 1948 quando a Organização das Nações Unidas decretou a declaração Universal dos Direitos Humanos, todos os homens passaram a ser considerados iguais. Estes Direitos dizem respeito ao igual atendimento das necessidades fundamentais de uma pessoa e surgem com regra do equilíbrio dos direitos das " pessoas portadoras de deficiência"

“ Todos são iguais perante a lei, sem distinção de qualquer natureza, garantindo-se aos brasileiros e aos estrangeiros residentes no País, a inviolabilidade do direito à vida, à liberdade, à igualdade, à segurança e à propriedade, (...)" .(Constituição da República Federativa do Brasil - Artigo $5^{\circ}$ ).

A constituição Brasileira promulgada em 1988 representa um avanço na proteção dos direitos do cidadãos e das " pessoas portadoras de deficiência” e, conforme Ana Clara Torres Ribeiro, “ recebeu a significativa denominação de constituição cidadã por expressar um 
marco, altamente relevante, do processo de redemocratização e por conter conquistas decorrentes da luta social desenvolvida durante e após o auge do período autoritário" (Ribeiro, 1996, p. 22 ).

A eliminação de barreiras de acesso nas ruas, edificações e transportes mereceram a atenção daqueles que pensaram e elaboraram a carta constitucional e a igualdade das pessoas portadoras de deficiência, pelo menos perante a lei, ficava garantida a possibilidade de integração destas pessoas na cidade permitindo sua circulação e o atendimento de suas necessidades espaciais.

Em 24 de outubro de 1989, estes direitos são ratificados pela Lei n. 7853 transferindo para Estados e Municípios a responsabilidade pela adoção efetiva execução de referentes ao assunto. E após a promulgação da nova Carta Magna do país “iniciou-se um processo semelhante nos estados em seguida dos municípios. A nova postura em relação à deficiência refletida em todas estas etapas nos 27 estados da Nação.” (Bieler, 1990, p.24).

Outros direitos como o acesso ao lazer (cinemas e casas de espetáculo), recebem tratamento semelhante e são direitos humanos interdependentes. Como aponta Araújo:

- “ Não se pode imaginar o direito a integração das pessoas portadoras de deficiência sem qualquer desses direitos instrumentais" (...) Sem transporte adaptado, não poderá comparecer ao local de trabalho, à escola e ao seu local de lazer.” (Araújo, 1994, p.61).

Segundo o PAMPD - Programa de Ação Mundial para as Pessoas com Deficiência equiparação de oportunidades é o " processo mediante o qual o sistema geral da sociedade , tal como meio físico, cultural, moradia e transporte, serviços sociais e de saúde, oportunidades de educação e de trabalho, vida cultural e social, inclusive instalações desportivas e de lazer, se fazem acessíveis a todos". (BRASIL, CORDE, 1994) 


\section{HOTÉIS SOB MEDIDA}

A Embratur lançou em 1999 o Manual de Recepção e Acessibilidade de pessoas portadoras de deficiência a empreendimentos e equipamentos turísticos para definir com detalhes de como deveriam ser os meios de hospedagem adaptados.

Embora não seja obrigatória a sua utilização, o manual mostra as adaptações que devem ser feitas nos projetos Hoteleiros.

Segundo o Manual de recepção e acessibilidade de pessoas portadoras de deficiência a empreendimentos e equipamentos turísticos, os hotéis por fornecerem alojamento e acomodações e, em muitos casos, alimentação, salas de reuniões e dependências de lazer, são os estabelecimentos que mais adaptações exigem para a acessibilidade de pessoas portadoras de deficiência. Essas adaptações, previstas no manual, abrangem acessos e circulações , portarias/recepção, quarto de dormir e sanitários e salas de reunião e outros.

Segundo a matriz de classificação de meios de hospedagem, Embratur 2002, a exigência da unidade habitacional (apartamento com banheiro privativo) adaptada para pessoas portadoras de deficiência foi instituída a partir de 1987, para a classificação de meios de hospedagem. Os estabelecimentos construídos anteriormente têm que dispor de facilidades e adaptações mesmo que não impliquem em reforma estrutural da edificação.

Muitos hotéis consideram que ter instalações adaptadas as pessoas portadoras de deficiência é simplesmente ter um vão da porta maior para passagem de cadeiras de rodas, mas não dispõem de elevador ou rampas para facilitar o acesso aos quartos . Segundo orientações do manual de recepção e acessibilidade de pessoas portadoras de deficiência a empreendimentos e equipamentos turísticos, as adaptações vão muito além disso.

O manual sugere as seguintes adaptações que vão desde o piso até a sinalização ,estas sugestões serão mencionadas a seguir : 
-Pisos:

Segundo o manual as áreas de acesso e circulações devem possuir superfície regular, firme, estável e antiderrapante, sobe qualquer condição climática, admitindo-se inclinação transversal da superfície de até $2 \%$. Para facilitar a identificação do percurso pelas pessoas portadoras de deficiência sensorial visual, é recomendado a utilização de faixas de piso com textura e cor diferenciadas.

As juntas de dilatação e grelhas devem ser embutidas no piso, transversalmente à direção do movimento e, preferencialmente, instaladas fora do fluxo principal de circulação.

Os capachos e forrações devem ser embutidos no piso e nivelados de maneira que a sobrelevação não exceda $1,5 \mathrm{~cm}$. As forrações devem ter as bordas firmemente fixadas ao piso e devem ser aplicadas de maneira a evitar eventual enrugamento de sua superfície.

Os hotéis devem possuir áreas para circulação de cadeiras de rodas, com dimensões que assegurem uma faixa de circulação livre de barreiras ou obstáculos de modo a permitir os diversos tipos de deslocamento, 0,80 m para circulação de uma cadeiras de rodas, 1,20 para circulação simultânea de uma pessoa e uma cadeira de rodas e $1,50 \mathrm{~m}$ para circulação simultânea de duas cadeiras de rodas.

São necessárias áreas mínimas para manobra de rotação sem deslocamento, 1,20 x 1,20 para rotação de $90^{\circ}, 1,50 \times 1,50$ para rotação de $180^{\circ}$ e um círculo de $1,50 \mathrm{~m}$ de diâmetro para rotação de $360^{\circ}$.

Para manobras de rotação com deslocamento o manual recomenda que a área ideal deve ser definida em função do raio necessário para efetuar a rotação, de modo a permitir a passagem por corredores de diferentes dimensões. 
O manual recomenda a existência de uma área de descanso fora do fluxo de circulação a cada $60 \mathrm{~m}$ para piso com até $3 \%$ de inclinação ou a cada $30 \mathrm{~m}$ para piso com 3 a $5 \%$ de inclinação.

As rampas devem obedecer aos limites estabelecidos na tabela abaixo, sendo que sua inclinação transversal deve ser, no máximo, de 2\%. A largura mínima admissível para as rampas é de 1,20, sendo recomendável 1,50 m. As rampas curvas devem ter inclinação máxima de $8,33 \%$ e raio mínimo de $3 \mathrm{~m}$, medidos no perímetro interno à curva.

Tabela 2 : Dimensionamento de rampas

\begin{tabular}{|c|c|l|l|}
\hline $\begin{array}{l}\text { Inclinação admissível } \\
\text { de cada segmento de } \\
\text { rampa (i) }\end{array}$ & $\begin{array}{l}\text { Desníveis máximos } \\
\text { De cada segmento de } \\
\text { rampas (d) }\end{array}$ & $\begin{array}{l}\text { Números máximos de } \\
\text { segmento de rampa } \\
(\mathrm{m})\end{array}$ & $\begin{array}{l}\text { Comprimentos } \\
\text { máximos de cada } \\
\text { segmento de rampa(s) } \\
(\mathrm{m})\end{array}$ \\
\hline $5.00(1: 20)$ & 1,500 & - & 30,00 \\
\hline $6,25(1: 16)$ & 1,000 & 14 & 16,00 \\
& 1,200 & 12 & 19,20 \\
\hline $8,33(1: 12)$ & 0,900 & 10 & 10,80 \\
\hline $10,00(1: 10)$ & 0,274 & 08 & 2,74 \\
& 0,500 & 04 & 7,50 \\
\hline $12,50(1: 8)$ & 0,750 & 01 & 1,46 \\
\hline
\end{tabular}

Fonte: Manual de recepção e acessibilidade de pessoas portadoras de deficiência a empreendimentos e equipamentos turísticos,1999.

Segundo o manual os patamares devem estar disponíveis no início e término da rampa, medindo no mínimo, 1,20 m na direção do movimento, além da área de circulação adjacente. Os patamares externos devem ter inclinação transversal, no máximo , $2 \%$. 
As Gulas de balizamentos devem ser previstas bordas laterais, em forma de ressalto, com altura mínima de $5 \mathrm{~cm}$ para a orientação e proteção dos portadores de deficiência.

Nos degraus e escada fixas não devem ser utilizados espelhos vazados ou com o piso saliente em relação ao espelho (bocel) nas áreas de circulação do fluxo principal. Os espelhos de degraus isolados deve ser superior a $15 \mathrm{~cm}$ e inferior a $18 \mathrm{~cm}$. As dimensões dos pisos e espelhos devem ser constantes em toda a escada. É permitida a inclinação transversal de até 2\% e largura mínima de 1,20 m para as escadas fixas. O primeiro e último degraus de um lance de escadas devem distar, pelo menos, 0,30 m de área de circulação adjacente.

Os patamares devem estar disponíveis na proporção de 1 a cada 3,20 m de desnível e sempre que houve mudança de direção.

É obrigatória a instalação de corrimão e guarda-corpo nos dois lados das rampas e escadas fixas, devendo ser construídos com materiais rígidos, firmemente fixados às paredes ou barras de suporte, oferecendo condições seguras para sua utilização.

- Equipamentos eletromecânicos de circulação:

Os elevadores devem atender à norma específica da ABNT (NBR 13994/9).

As portas devem possuir vão livre mínimo de $0,80 \mathrm{~m}$, inclusive os dos elevadores, ausência de esforço superior a 35,61N para puxa-la ou empurra-la, abertura em único movimento, com maçanetas do tipo alavanca; revestimentos resistente a impactos provocados por bengalas, muletas e cadeiras de rodas(pelos menos na sua parte inferior até uma altura mínima de 0,40 m). 
Características específicas:

- Portas de sanitários com barra horizontal

- Portas localizadas junto ao patamar com previsão de vestíbulo de, no mínimo, 1,50 m de largura por 1,20 m de comprimento, além da área de abertura da porta de largura por 1,20m de comprimento, além da área de abertura da porta.

- Portas localizadas em áreas confinadas ou em meio à circulação com um espaço mínimo de $0,60 \mathrm{~m}$, contíguo ao vão de abertura.

- Portas de vaivém com visor localizado no lado oposto às dobradiças, de largura mínima de $0,20 \mathrm{~m}$, com sua face inferior situada entre $0,40 \mathrm{~m}$ e o $0,90 \mathrm{~m}$ de piso e a face superior no mínimo a $1,50 \mathrm{~m}$.

- Portas de correr com trilho ou guias inferiores que não projetam acima da superfície do piso.

- Previsão de outro acesso sinalizado sempre que houver barreiras e obstáculos, do tipo portas giratórias, catracas, etc.

- Janelas:

As janelas devem situar-se em altura acessível ao alcance visual de pessoas em cadeiras de rodas, de modo que cada uma das suas folhas possa ser aberta com um único movimento e um mínimo de esforço. Os comandos e trincos devem ser do tipo de alavanca, situando-se na altura do limite de ação e alcance manual do portador de deficiência.

\section{- Portaria/Recepção/Atendimento:}

Devem possuir balcões de atendimento automáticos ou prever o rebaixamento de uma parte do balcão a uma altura livre mínima de 0,70 do piso, que permita a aproximação frontal de pelo menos uma cadeira de rodas, possibilitando, ainda , o atendimento a pessoas idosas, gestantes e de baixa estatura, que precisam sentar para preencher fichas e cheques. Esse trecho 
deve ser sinalizado com o Símbolo Internacional de Acesso e deve dispor sempre de uma cadeira próxima para utilização das pessoas anteriormente referidas.

- Quartos de Dormir dos apartamentos de meio de hospedagem:

Um quarto confortável para pessoas em cadeira de rodas deve permitir a rotação completa $\left(360^{\circ}\right)$ desse equipamentos, dispondo, para esse fim, de um circulo com 1,50 m de diâmetro.

Figura 1: diâmetro de rotação de uma cadeira de rodas

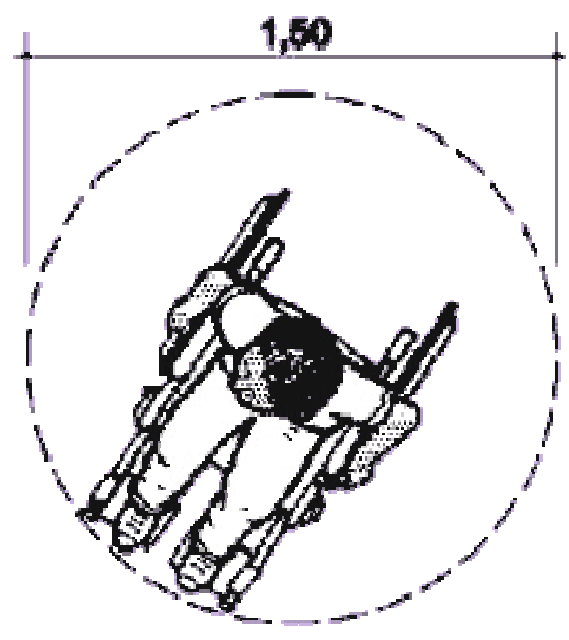

Fonte: www.deca.com.br 
Todos os comandos de aparelhos, interruptores e tomadas devem estar dentro da altura de acessibilidade do portador de deficiência.

Figura 2: limites de alcance visual

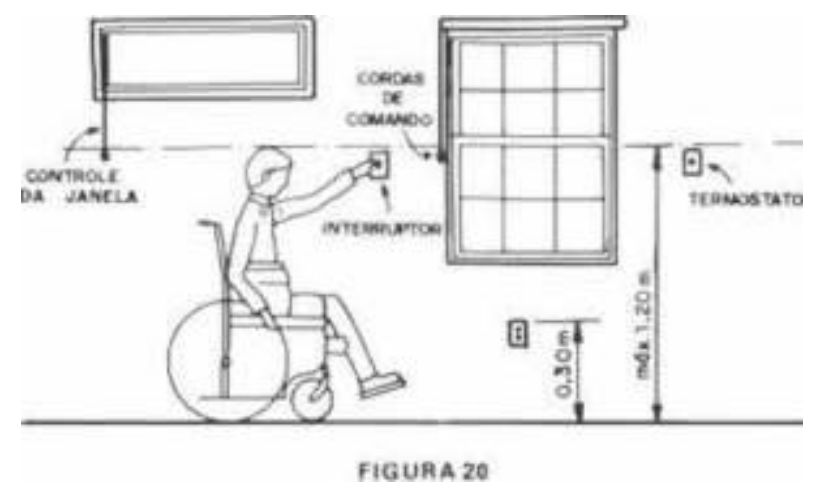

Fonte: www.munizengenharia.com.br

As camas, poltronas, cadeiras e bancos devem ser providos de encosto e ter uma altura um pouco menor que a do assento da cadeira de rodas, cerca de 0,46 de altura do piso, preferencialmente com espaço livre ou reentrância na parte inferior. 
Os armários devem ter sua parte inferior instalada a $0,30 \mathrm{~m}$ do piso, deixando o espaço abaixo livre de qualquer saliência ou obstáculo, de modo a permitir a aproximação frontal. A altura máxima para a utilização do armário deve ser de $1,20 \mathrm{~m}$ a partir do piso. Os puxadores e fechaduras devem estar na faixa de conforto de $0,80 \mathrm{~m}$ a $1,00 \mathrm{~m}$ de altura do solo.

Figura 3: Armários

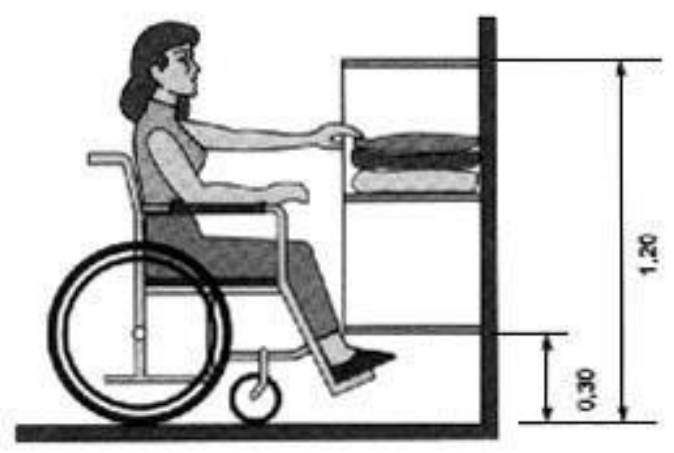

Fonte: www.ibdd.org.br

\section{- Sanitários}

As áreas sociais devem situar-se em locais acessíveis, próximos à circulação principal, devidamente sinalizados, com, no mínimo, 5\% do total de cada peça adequado ao uso de portador de deficiência ambulatória ou, em caso de sanitários menores, com uma unidade de cada peça adequada a esse fim. Essas disposições aplicam-se tanto ao sanitário masculino quanto no feminino.

Os sanitários devem ter características específicas que facilitem a manobra, áreas de aproximação e transferência, permitindo a utilização da peça sanitária pelo portador de deficiência, mediante, respectivamente, a transposição da pessoa para a peça ou a chega junto à mesma, para dela fazer uso. Devem ter dimensões de $1,10 \mathrm{~m}$ por 0,80 e estar situados frontal ou lateralmente à peça. 
São necessárias barras sanitárias para apoio e transferência do portador de deficiência, barras horizontais localizadas na lateral e no fundo, junto à bacia, fixadas a $0,30 \mathrm{~m}$ de altura em relação ao assento da bacia, dispondo de comprimento mínimo de $0,90 \mathrm{~m}$ e distância máxima de $0,24 \mathrm{~m}$ da face lateral da bacia. A barra lateral deve estar posicionada de modo a avançar $0,50 \mathrm{~m}$ da extremidade frontal da barra.

-Chuveiro e ducha:

O boxe para chuveiro/ducha deve possuir área de transferência . O boxe deve ser provido de barra horizontal e vertical localizada na parede de encosto do banco .

Figura 4: Box do chuveiro

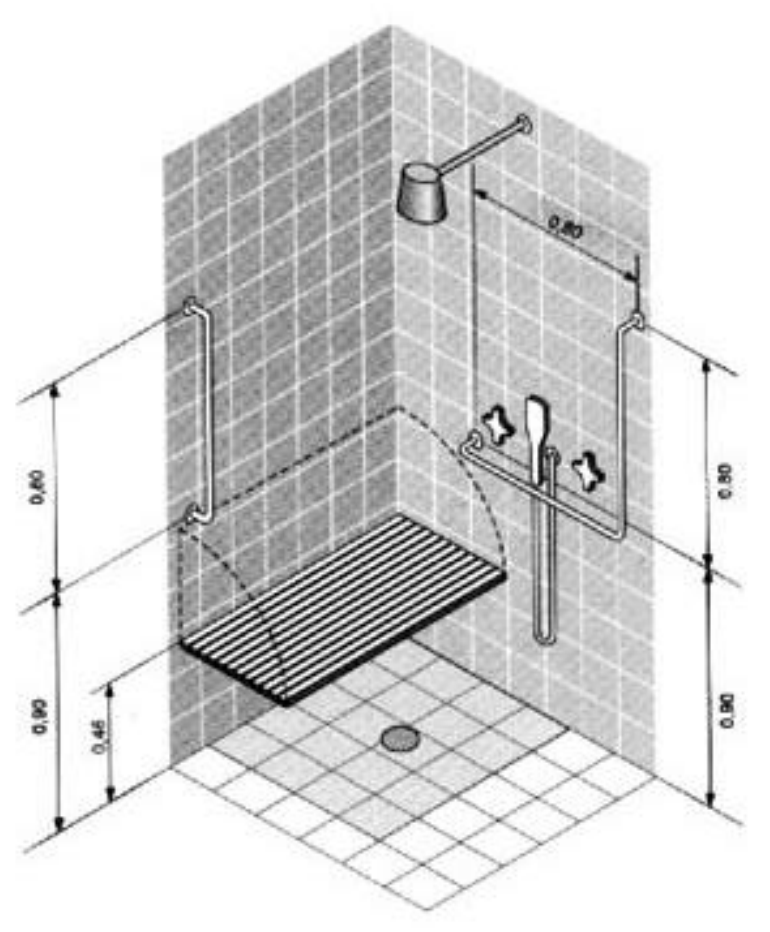

Fonte: www.ibdd.org.br 


\section{- Comunicação e Sinalização:}

- O manual adota como forma de comunicação : visual, tátil e auditiva

A indicação de visual de acessibilidade às edificações e equipamentos deve ser feita por meio do Símbolo Internacional às edificações e equipamentos deve ser feita por meio do Símbolo internacional de Acesso . O símbolo é composto pelo pitograma inserido em quadrilátero e, em sua utilização devem ser mantidas as proporções indicadas no desenho da referida figura. As cores usadas para este símbolo devem ter contraste nítido, sendo o fundo na cor Azul-escura e o pictograma brancos. O Símbolo Internacional de acesso deve ter dimensões e localização adequadas, para sua fácil visualização.

Figura 5 : Símbolo Internacional de Acesso

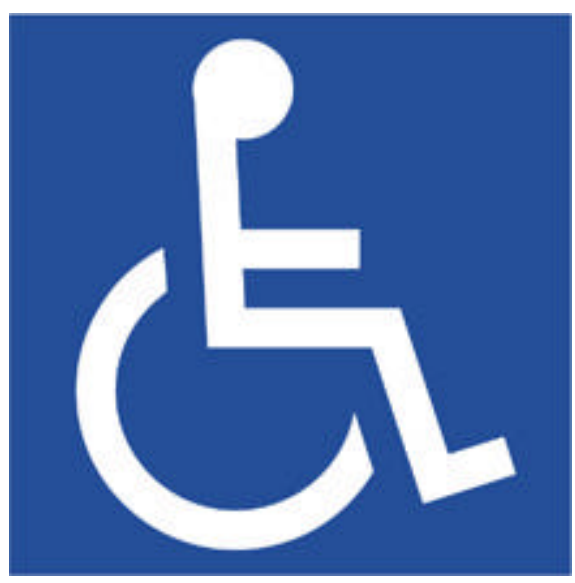

Fonte: www.ibdd.org.br 
A comunicação tátil é dirigida às pessoas portadoras de deficiência visual, por meio de informações em Braile e diferenças de textura e superfícies.

A comunicação auditiva é dirigida às pessoas portadoras de deficiência visual, por meio da sinalização sonora padronizada.

- Sinalização:

Nas entrada principais dos empreendimentos que tenham acesso adequado às pessoas portadoras de deficiência, deve existir o Símbolo Internacional de Acesso. Nas circulações que possibilitem acesso às pessoas portadoras de deficiência devem ser sinalizadas com o Símbolo Internacional de Acesso, acompanhado quando necessário, de seta indicativa do sentido de deslocamento.

Os degraus, rampas e escadas fixas devem ter faixas com texturas diferenciadas, com o mínimo de 0,28 m, ocupando toda a largura dos degraus, rampas e escadas fixas, localizadas antes do início e após o término da mudança de inclinação ou de plano. As rampas em passeio devem ter faixa de piso com textura diferenciada da faixa do passeio e da faixa do próprio piso.

Junto às portas dos elevadores para pessoas portadoras de deficiência deve ser afixado o Símbolo Internacional de Acesso. As botoeiras e comandos devem ser acompanhados de comunicação tátil. Para um número de paradas superior a dois, deve também haver comunicação auditiva, dentro da cabine do elevador, indicando o andar onde o elevador se encontra parado.

Pode-se observar que as sugestões são numerosas e cheias de detalhes, o que requer bastante atenção dos arquitetos. 


\section{SITUAÇÃO HOTELEIRA DE BRASÍLIA}

A história da hotelaria em Brasília teve início com os hotéis de propriedades particulares, fazendeiros, usineiros e empresários que viram na cidade uma oportunidade de investimento na hotelaria. Durante quase 40 anos a cidade teve como oferta os empreendimentos com administração familiar, sem a menor preocupação com os padrões internacionais de qualidade e atendimento.

Com a chegada das grandes redes nacionais e internacionais os antigos hoteleiros se encontraram em uma situação altamente competitiva. Os novos hotéis, com instalações modernas, padronizadas e mão-de-obra qualificada tornaram-se uma ameaça para os antigos hotéis que possuem instalações ultrapassadas e disfuncionais.

Na reportagem Procuram-se hóspedes, publicada no Correio Braziliense de 13 de maio de 2002, Érica Montenegro comenta que com a entrada das grandes redes hoteleiras, desde 2000; 11 flats e hotéis foram inaugurados no DF e o número de UH saltou de 5000 para 6511. . A situação em 2002 era a seguinte:

- 44 hotéis e flats no Plano Piloto;

- 19 hotéis com até quatro andares;

- Oferta de 6511 apartamentos, totalizando 18 mil leitos;

- 740 m2 de área construída;

- Faturamento anual girava em torno de $\mathrm{R} \$ 265$ milhões;

- 5 mil pessoas empregadas na hotelaria. 


\section{METODOLOGIA E TÉCNICAS}

Para o levantamento dos dados desta pesquisa foram utilizadas as metodologias quantitativas e qualitativas.

Vários autores defendem a idéia de combinar métodos quantitativos e qualitativos com o intuito de proporcionar uma base contextual mais rica para interpretação e validação dos resultados (Kaplan\& Duchon, 1988).

A pesquisa qualitativa é geralmente associada à pesquisa exploratória interpretativa, enquanto a pesquisa qualitativa é associada a estudos positivistas confirmatórios (Wildemuth,1993).

Os métodos quantitativos foram utilizados para definir a quantidade de hotéis que possuem adaptação para PPD e a quantidade de itens adaptados e os métodos qualitativos serviram para avaliar o grau de adaptação de cada hotel, através de observação e comparação com a literatura.

A etapa preliminar da pesquisa consistiu no estudo dos aspectos considerados importantes para acessibilidade de PPD aos hotéis. O estudo detalhado do Manual de recepção e acessibilidade aos empreendimentos e equipamentos turísticos e suas recomendações de adaptação para os hotéis.

Em pesquisas qualitativas, a consistência pode ser checada por meio de exame detalhado da literatura e comparando os achados ou observações com aqueles da literatura. Outra maneira é utilizar a triangulação, isto é, empregar métodos diferentes de coleta dos mesmos dados e comparar os resultados (Glazier, 1992).

Estranhamente, a pesquisa qualitativa, assim como a pesquisa quantitativa, teve seus antecedentes nas ciências naturais e na filosofia . Exemplos: (Glazier,1992) 
- Newton - renomado matemático utilizou o abordagem qualitativa para demonstrar o efeito prisma do espectro luminoso;

- Darwin - estabeleceu a teoria da evolução das espécies a partir de observações das diferenças entre espécies da vida selvagem e análise dos dados puramente qualitativos, sem qualquer esforço de medir essas diferenças;

Os métodos qualitativos, em sua maioria, são derivados dos estudos de campo e etnográficos da antropologia (Patton, 1980).

A pesquisa foi realizada em 44 (quarenta e quatro) hotéis, todos eles no Plano Piloto.

Fases da pesquisa:

- A primeira etapa da pesquisa consistiu no levantamento dos hotéis existentes na cidade, endereço e telefone de cada hotel.

- A segunda etapa consistiu na identificação dos hotéis que possuem instalações adaptadas para acessibilidade de PPD. O primeiro contato foi feito por telefone para identificar os hotéis que possuem instalações adaptadas para PPD.

- A terceira etapa consistiu na visita aos hotéis identificados na segunda etapa, apenas os que possuem instalações adaptadas para PPD, foram visitados 10 (dez ) hotéis, para avaliação das condições de acessibilidade de cada hotel.

Na pesquisa qualitativa, o pesquisador é um interpretador da realidade (Bradley,1993).

As principais características dos métodos qualitativos são a imersão do pesquisador no contexto e a perspectiva interpretativa de condução da pesquisa (Kaplan \& Duchon,1988) 


\subsection{AVALIAÇÃO}

O primeiro item avaliado foi a existência ou não de adaptação para PPD nos hotéis , de acordo com essa avaliação dividiu-se os hotéis e dois grupos distintos:

- Hotéis com adaptação para PPD

- Hotéis sem adaptação para PPD

Na terceira etapa da pesquisa, que consistiu na visita aos hotéis com adaptação para PPD, foram avaliados os seguintes itens:

- Acessos e circulações: áreas para circulação de cadeiras de rodas, rampas, desnível, corrimão , elevadores, esteiras rolantes, portas e janelas;

- Portaria, Recepção e atendimento;

- UHS adaptadas;

- Sanitários em apartamentos;

- Estacionamento;

- Comunicação e Sinalização; 


\section{RESULTADOS DA PESQUISA}

O resultado da segunda etapa da pesquisa que procurou identificar quais os hotéis que possuem adaptações para acessibilidade de PPD foi o seguinte:

A pesquisa mostrou que dos 44 (quarenta e quatro ) hotéis pesquisados apenas 18 (dezoito) hotéis possuem instalações adaptadas para PPD .

\begin{tabular}{|c|c|c|}
\hline $\begin{array}{c}\text { Hotéis com adaptação para } \\
\text { PPD }\end{array}$ & Hotéis sem adaptação para PPD & Total \\
\hline 18 & 26 & 44 \\
\hline $40,91 \%$ & $59,09 \%$ & $100 \%$ \\
\hline
\end{tabular}

Dos hotéis que possuem adaptação, 8 (oito ) pertencem as grandes redes hoteleiras recentemente instaladas na cidade

\begin{tabular}{|c|c|c|}
\hline $\begin{array}{c}\text { Hotéis pertencentes as } \\
\text { grandes redes }\end{array}$ & Hotéis tradicionais & Total \\
\hline 8 & 10 & 18 \\
\hline $44,44 \%$ & $55,56 \%$ & $100 \%$ \\
\hline
\end{tabular}




\section{1 - ADAPTAÇÃO DOS HOTEIS}

Através das visitas aos hotéis foi possível confrontar a realidade existente em cada hotel com as orientações do Manual de recepção e acessibilidade de pessoas portadoras de deficiência a empreendimentos e equipamentos turísticos.

De acordo com os itens estabelecidos para a avaliação , constatou-se o seguinte:

- Acessos e circulações:

- O hotel possui acessos e circulações de cadeiras de rodas ?

\begin{tabular}{|c|c|c|}
\hline Sim & Não & Total \\
\hline 9 & 1 & 10 \\
\hline $90 \%$ & $10 \%$ & $100 \%$ \\
\hline
\end{tabular}

Dos 10 (dez )hotéis visitados apenas 1 (um) hotel possui barreiras arquitetônicas que dificultam o acesso e circulação de cadeiras de rodas, ausência de rampas na entrada e escadas que impedem o acesso aos elevadores. Os demais hotéis apresentaram um aspecto satisfatório para circulação de cadeiras de rodas, com exceção de algumas adaptações improvisadas e que não seguem os critérios estabelecidos no Manual de recepção e acessibilidade de pessoas portadoras de deficiência a empreendimentos e equipamentos turísticos, mas de certa forma permitem o acesso aos espaços. 
- Possui rampas?

\begin{tabular}{|c|c|c|}
\hline Sim & Não & Total \\
\hline 9 & 1 & 10 \\
\hline $90 \%$ & $10 \%$ & $100 \%$ \\
\hline
\end{tabular}

Dos 10 (dez) hotéis visitados apenas 1 (um) hotel não possui rampas de acesso aos espaços, o mesmo que apresentou barreiras que dificultam o acesso e circulação de cadeiras de rodas.

Os demais hotéis possuem rampas, mas as mesmas não obedecem aos limites de inclinação e larguras recomendadas pelo Manual de recepção e acessibilidade de pessoas portadoras de deficiência a empreendimentos e equipamentos turísticos.

- Possui corrimão nas escadas ?

\begin{tabular}{|c|c|c|}
\hline Sim & Não & Total \\
\hline 10 & 0 & 10 \\
\hline $100 \%$ & $0 \%$ & $100 \%$ \\
\hline
\end{tabular}

Dos 10 (dez) hotéis visitados todos os hotéis visitados possuem corrimão nas escadas . 
- Possui corrimão nas rampas?

\begin{tabular}{|c|c|c|}
\hline Sim & Não & Total \\
\hline 0 & 10 & 10 \\
\hline $0 \%$ & $100 \%$ & $100 \%$ \\
\hline
\end{tabular}

Dos 10 (dez) hotéis visitados nenhum hotel possui corrimão nas rampas

Possui esteiras rolantes?

\begin{tabular}{|c|c|c|}
\hline Sim & Não & Total \\
\hline 0 & 10 & 10 \\
\hline $0 \%$ & $100 \%$ & $100 \%$ \\
\hline
\end{tabular}

Dos 10 (dez) hotéis visitados nenhum hotel possui esteira rolante

Portas:

- Possui revestimento resistente a impactos provocados por bengalas, muletas e cadeiras de rodas?

\begin{tabular}{|c|c|c|}
\hline Sim & Não & Total \\
\hline 0 & 10 & 10 \\
\hline $0 \%$ & $100 \%$ & $100 \%$ \\
\hline
\end{tabular}

Dos 10 hotéis visitados, nenhum possui revestimento resistente a impactos provocados por bengalas, muletas e cadeiras de rodas. 
- Possui janelas com altura acessível ao alcance visual de pessoas em cadeiras de rodas?

\begin{tabular}{|c|c|c|}
\hline Sim & Não & Total \\
\hline 0 & 10 & 10 \\
\hline $0 \%$ & $100 \%$ & $100 \%$ \\
\hline
\end{tabular}

Dos 10 (dez ) hotéis visitados nenhum possui janela no apartamento, as janelas são substituídas por varandas. As varandas possuem portas de correr, com trilhos projetados acima da superfície do piso, dificultando o acesso de pessoas em cadeiras de rodas.

- Portaria/Recepção/Atendimento

- Possui balcão de atendimento automático ou prever o rebaixamento de uma parte do balcão?

\begin{tabular}{|c|c|c|}
\hline Sim & Não & Total \\
\hline 0 & 10 & 10 \\
\hline $0 \%$ & $100 \%$ & $100 \%$ \\
\hline
\end{tabular}

Os 10(dez ) hotéis visitados não possuem balcões de atendimento automáticos ou rebaixamento de uma parte do balcão a uma altura que permita a aproximação frontal de uma cadeira de rodas. 
- Quartos de dormir dos apartamentos (UH)

- Possui espaço para circulação de cadeiras de rodas?

\begin{tabular}{|c|c|c|}
\hline Sim & Não & Total \\
\hline 0 & 10 & 10 \\
\hline $0 \%$ & $100 \%$ & $100 \%$ \\
\hline
\end{tabular}

O maior problema identificado nas UHS adaptadas é a ausência de espaço para a rotação de $360^{\circ}$ nos apartamentos, nos 10 hotéis visitados não há um espaço com 1,50 m de diâmetro para a rotação de uma cadeira de rodas.

- Possui controles, comandos e puxadores dentro da altura de acessibilidade do PPD?

\begin{tabular}{|c|c|c|}
\hline Sim & Não & Total \\
\hline 10 & 0 & 10 \\
\hline $100 \%$ & $0 \%$ & $100 \%$ \\
\hline
\end{tabular}

Os comandos de aparelhos, interruptores e tomadas estão dentro da altura de acessibilidade no 10 (dez) hotéis visitados.

- Possui armários com altura adequada , máximo de 1,20m , a partir do piso?

\begin{tabular}{|c|c|c|}
\hline Sim & Não & Total \\
\hline 4 & 6 & 10 \\
\hline $40 \%$ & $60 \%$ & $100 \%$ \\
\hline
\end{tabular}

Dos 10 hotéis visitados apenas 4 hotéis possuem armários que permitem a aproximação frontal e altura adequada para utilização. Os demais hotéis possuem armários com altura acima de 1,20 m, que não permite a utilização por pessoas em cadeiras de rodas ou pessoas de baixa estatura. 
- Possui armários com a parte inferior instalada a 0,30 m do piso, deixando o espaço abaixo livre de qualquer saliência ou obstáculo?

\begin{tabular}{|c|c|c|}
\hline Sim & Não & Total \\
\hline 0 & 10 & 10 \\
\hline $0 \%$ & $100 \%$ & $100 \%$ \\
\hline
\end{tabular}

Nenhum hotel possui armário com a parte inferior instalada a $0,30 \mathrm{~m}$ do piso.

-Sanitários em apartamentos

- Possui barra sanitária?

\begin{tabular}{|c|c|c|}
\hline Sim & Não & Total \\
\hline 7 & 3 & 10 \\
\hline $70 \%$ & $30 \%$ & $100 \%$ \\
\hline
\end{tabular}

Dos 10 (dez) hotéis visitados 7 (sete) possuem barras sanitárias para apoio e transferência do PPD .

- Possui banco no Box?

\begin{tabular}{|c|c|c|}
\hline Sim & Não & Total \\
\hline 3 & 7 & 10 \\
\hline $30 \%$ & $70 \%$ & $100 \%$ \\
\hline
\end{tabular}

Dos 10 (dez ) hotéis visitados somente 3 hotéis possuem banco no Box, banco fixo, 1 hotel possui uma cadeira de rodas para banho e os demais hotéis possuem bancos de plástico, não aconselhável pelo risco de acidentes. 
-Possui lavatório suspenso, sem coluna ou gabinete de sustentação?

\begin{tabular}{|c|c|c|}
\hline Sim & Não & Total \\
\hline 7 & 3 & 10 \\
\hline $70 \%$ & $30 \%$ & $100 \%$ \\
\hline
\end{tabular}

Dos 10 (dez) hotéis visitados , 7 possuem lavatório suspenso, que permite a aproximação de cadeiras de rodas.

De maneira geral os hotéis possuem banheiros adaptados com barras de apoio e transferência, banco no Box, lavatório suspenso, sem coluna ou gabinete, com exceção de alguns hotéis que improvisam com bancos de plásticos. Em nenhum hotel a adaptação foi aprovada em $100 \%$ dos itens.

- Estacionamento:

- Possui vagas para estacionamento de veículos dirigidos por pessoas PPD?

\begin{tabular}{|c|c|c|}
\hline Sim & Não & Total \\
\hline 10 & 0 & 10 \\
\hline $100 \%$ & $0 \%$ & $100 \%$ \\
\hline
\end{tabular}

Dos 10 (dez ) hotéis visitados todos possuem vagas para veículos dirigidos por PPD. As vagas são sinalizadas com o Símbolo Internacional de acesso. 
Sinalização:

- Possui Sinalização feita através do Símbolo Internacional de Acessibilidade?

\begin{tabular}{|c|c|c|}
\hline Sim & Não & Total \\
\hline 1 & 9 & 10 \\
\hline $10 \%$ & $90 \%$ & $100 \%$ \\
\hline
\end{tabular}

Dos 10 (dez) hotéis visitados apenas um hotel possui o Símbolo Internacional de Acesso indicando a acessibilidade de PPD. 


\section{CONCLUSÃO}

O resultado da pesquisa demonstrou que a maioria dos hotéis de Brasília não possui instalações adequadas, que permitam a acessibilidade de pessoas portadoras de deficiência. Dos 44 (quarenta e quatro) hotéis pesquisados apenas 18 (dezoito) hotéis possuem instalações adaptadas para PPD.

Constatou-se que muitos hotéis de Brasília não seguem as orientações do Manual de recepção e acessibilidade de pessoas portadoras de deficiência a empreendimentos e equipamentos turísticos. Embora 18 (dezoito) hotéis possuam instalações adaptadas para PPD , a maioria dos hotéis não segue totalmente as orientações do Manual. Alguns hotéis apresentam instalações improvisadas, sem os parâmetros ditados pelo manual.

A pesquisa mostrou que a quantidade de hotéis que possuem adaptações para PPD é pequena em relação ao número de hotéis existentes na cidade. Constatou-se que os hotéis recém instalados na cidade e de bandeiras, nacionais e internacionais, possuem as melhores condições para recepção e acessibilidade de PPD.

Em quase todos os hotéis visitados as UHS adaptadas para PPD encontram-se em uma localização não muito privilegiada, no primeiro andar, geralmente sem vista e em frente aos elevadores ou próximas das áreas mais barulhentas do hotel.

A maioria dos hotéis, de construção mais antiga, não possui nenhum tipo de adaptação para PPD, esses hotéis oferecem como alternativas de hospedagem UH improvisadas, sem porta nos banheiros, no térreo, próximo aos elevadores ou escadas, acesso aos espaços por elevadores de serviço ou por locais não muito agradáveis.

Constatou-se que em alguns hotéis que possuem a UH adaptada estão preocupados apenas em oferecer o apartamento adaptado, sem qualquer preocupação de como o hóspede 
terá acesso até ele. Em dois hotéis visitados, que possuem a UH adaptada, o hóspede não têm acesso ao hotel devido a ausência de rampas na entrada e a presença de escadas no trajeto. A opção de acesso ao hotel é por entradas de serviço, pelos fundos do hotel . Gerando um constrangimento ao hóspede, não é nada agradável chegar ao hotel pela porta dos fundos.

Outro fator importante é que os hotéis que possuem adaptações para PPD atendem a exigência da Embratur, de pelo menos uma UH com banheiro privativo adaptado para PPD, a maioria possui apenas uma UH adaptada. Na maioria dos hotéis pesquisados não há como hospedar mais de uma pessoa portadora de deficiência, simultaneamente no mesmo hotel.

O resultado das visitas aos hotéis demonstrou que o declarado como adaptação para PPD pelos 18 (dezoito) hotéis, dos 44 hotéis pesquisados, não obedece todas as exigências do manual de recepção e acessibilidade de pessoas portadoras de deficiência aos empreendimentos e equipamentos turísticos. As adaptações limitam-se a rampas de acesso e uma UH parcialmente adaptada. O Portador de deficiência continua sendo excluído e discriminado pelos hoteleiros.

Sugere-se como complemento desta pesquisa um estudo da demanda de reservas para PPD nos hotéis da cidade para identificar, se há demanda para esse público nos hotéis da cidade. 


\section{REFERÊNCIAS BIBLIOGRÁFICAS}

ARAUJO, Luiz Alberto David. A proteção Constitucional das Pessoas Portadoras de Deficiência.Brasília: CORDE,1994.

BIELLER, Rosângela Berman.Os Direitos das Pessoas Portadoras de Deficiência no Brasil.Rio de Janeiro: Rotary Club do Rio de Janeiro,1990.

BRASIL. Constituição da República Federativa do Brasil: promulgada em 5 de outubro de 1988.

BRASIL. Lei №7853, de 24 de outubro de 1989. Dispõe sobre o apoio às pessoas portadoras de deficiência, sua integração social, sobre a Coordenação Nacional para a Integração da Pessoa Portadora de Deficiência,CORDE,1989.

CANCELLA, Ricardo Nogueira. Os portadores de necessidades especiais nos transportes públicos: Quem são? Quantos são? O que fazer?.Dissertação de Mestrado. Universidade de Brasília,1994.120 pág.

CEDIPOD- Centro de documentação e informação do portadora de deficiência- disponível em $<$ http://www.cedidpod.org.br>, acesso em julho de 2003.

CERATTI, Mariana. Cadê a rampa?.Correio Braziliense.Brasília/DF,18 de junho de 2003.Lugares.

CORDE-Coordenadoria Nacional para integração da Pessoa Portadora de Deficiência disponível em: <http://www.mj.gov.br>, acesso em julho de 2003.

CORDE,1994. Coordenadoria Nacional para a Integração da Pessoa Portadora de Deficiência. Os Direitos das Pessoas Portadoras de Deficiência, Brasília-DF. 
EMBRATUR, 1999, Manual de recepção e acessibilidade de pessoas portadoras de deficiência a empreendimentos e equipamentos turísticos.1999.

GLAZIER, Jack D.\& POWELL, Ronald R. Qualitative research in information management.Englewood. Libraries Unlimited.1992.

IBGE, Censo 2000. Disponível na Internet em $\leqslant$ http://www.ibge.gov.br>, acesso em outubro de 2003.

KAPLAN, Bonnie \& Duchon, Dennis. Combining qualitative and quantitative methods in a LIS Master's program.Library Trends,Spring 1998.

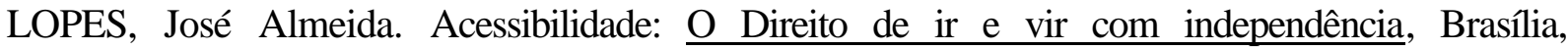
jul.,2003. Disponível na Internet em: <http://www.entreamigos.com.br/semimagem /textos>, acesso em 20 de out. 2003.

MONTENEGRO, Érica. Procuram-se hóspedes. Correio Braziliense. Brasília/DF. 13 de maio de 2002, Cidades.

MONTENEGRO, Érica. Onde a história se hospedou. Correio Braziliense. Brasília/DF. 08 de abril de 2003. Cidades.

NBR 9050/94 - ABNT- Acessibilidade de pessoas portadoras de deficiência a edificações, espaço, mobiliários e equipamentos urbanos.

OLIVEIRA, Moacyr Velloso Cardoso. Previdência Social: Reabilitação Profissional, Revista LTr. São Paulo,1981. 
ONU,1975.Declaração dos Direitos das Pessoas Deficientes. Disponível na Internet em: $<$ http://www.lerparaver.com/legislação/internacional_deficientes.html $>\quad$ acesso $\quad$ em $\quad 15$ de out.2003.

PATTON, Michael, Q. Qualitative evaluation methods. Bervely Hills, CA: Sage, 1980

PRADO, Adriana Romeiro de Almeida. Ambientes Acessíveis: Ser Autônomo e ter independência. Disponível na Internet em: <http://www.entreamigos.com.br/semimagem /textos>, acesso em 20 de out. 2003.

RIBEIRO, Ana Clara Torres. Urbanidade e Vida Metropolitana. Rio de Janeiro: JobranLivraria e Editora, 1996.

VILLATORE, Marco Antonio. O Decreto . 3298, de 20.12.99 - A pessoa portadora de deficiência no Direito do Trabalho brasileiro e o tema no Direito do Trabalho comparado, in Revista LTR 64-05/618-619

WILDEMUTH, Bárbara M. Post-positivist research: two examples of methodological pluralism.Library Quarterly,v.63,n.4 .1993. 


\section{APÊNDICE}

\section{APÊNDICE A}

Check-list dos itens avaliados no hotéis

Hotel:

Quantidade de UH:

Quantidade de UH adaptada para PPD:

1- Possui acessos e circulações de cadeiras de rodas?

( ) Sim ( ) Não

Comentários:

2- Possui rampas?

( ) Sim ( ) Não

Comentários: 
3- Possui corrimão nas escadas ?

Sim ( ) Não ( )

Comentários:

4- Possui corrimão nas rampas?

Sim ( ) Não ( )

Comentários:

5- Possui esteiras rolantes?

Sim ( ) Não ( )

Comentários:

6- Possui revestimento resistente a impactos provocados por bengalas, muletas e cadeiras de rodas?

Sim ( ) Não ( )

Comentários: 
7- Possui janelas com altura acessível ao alcance visual de pessoas em cadeiras de rodas?

Sim ( ) Não ( )

Comentários:

8 - Possui balcão de atendimento automático ou prever o rebaixamento de uma parte do balcão?

Sim ( ) Não ( )

Comentários:

9- Possui espaço para circulação de cadeiras de rodas no quarto ?

Sim ( ) Não ( )

Comentários:

10 - Possui controles, comandos e puxadores dentro da altura de acessibilidade do PPD?

Sim ( ) Não ( ) 
Comentários:

11- Possui armários com altura adequada , máximo de 1,20m , a partir do piso?

$\operatorname{Sim}($ ) Não ( )

Comentários:

12 -Possui armários com a parte inferior instalada a $0,30 \mathrm{~m}$ do piso, deixando o espaço abaixo livre de qualquer saliência ou obstáculo?

$\operatorname{Sim}(\quad$ ) Não ( )

Comentários:

13 - Possui barra sanitária?

Sim ( ) Não ( )

Comentários:

15 - Possui banco no Box?

$\operatorname{Sim}($ ) Não ( ) 
Comentários:

16-- Possui lavatório suspenso, sem coluna ou gabinete de sustentação?

Sim ( ) Não ( )

Comentários:

17 - Possui vagas no estacionamento para veículos dirigidos por PPD?

Sim ( ) Não ( )

Comentários:

18 - Possui Sinalização feita através do Símbolo Internacional de Acessibilidade?

Sim ( ) Não ( )

Comentários: 